(c) American Dairy Science Association, 2007.

\title{
Application of Fluorescence Spectroscopy for Monitoring Changes in Nonfat Dry Milk During Storage
}

\author{
X. Liu and L. E. Metzger ${ }^{1}$ \\ MN-SD Dairy Foods Research Center, Department of Food Science and Nutrition, University of Minnesota, St. Paul 55108
}

\begin{abstract}
The objective of this study was to determine if fluorescence spectroscopy could be used to characterize the biochemical characteristics of nonfat dry milk (NDM) caused by manufacturing and storage conditions. Nine low-heat NDM samples were collected from 3 manufacturers and stored at 4 temperatures $(4,22,35$, and $50^{\circ} \mathrm{C}$ ) for $8 \mathrm{wk}$. The spectra of Maillard products, tryptophan, and riboflavin were recorded and analyzed with principal components analysis. Colorimetric indices L*, $a^{*}$, and $b^{*}$ were also determined. The before-storage NDM samples collected from each manufacturer had different fluorescent characteristics. Inconsistency was observed for the NDM samples collected from 1 manufacturer, whereas the samples from the other 2 manufacturers displayed consistent fluorescence characteristics. Biochemical reactions, such as Maillard reaction, modification of the tryptophan environment, and degradation of riboflavin occurred during the manufacturing process. For each of the data collections, discrimination of the NDM samples stored at $50^{\circ} \mathrm{C}$ from the samples stored at 4,22 , and $35^{\circ} \mathrm{C}$ was observed in the similarity maps. The factor loadings of the first 2 principal components for the fluorescence spectra of the samples before storage were similar to the principal components analysis results of the samples during storage. It appears that similar factors are responsible for the variation in the samples before storage and their changes during storage. Additionally, storage of the samples at $50^{\circ} \mathrm{C}$ accelerated these reactions. The results demonstrate that front-face fluorescence spectroscopy, coupled with multivariate statistical methods, can be utilized as an analytical technique to monitor variation in NDM samples from different manufacturers and changes during storage.
\end{abstract}

Key words: nonfat dry milk, storage, fluorescence spectroscopy, chemometrics

Received July 5, 2006.

Accepted August 31, 2006.

${ }^{1}$ Corresponding author: lmetzger@umn.edu
INTRODUCTION

Nonfat dry milk (NDM) is a common type of milk powder produced in the United States and is an important ingredient used in a variety of products. Numerous factors have been shown to have a significant impact on the performance characteristics of NDM including manufacturing conditions (Guyomarc'h et al., 2000) and storage conditions (Troyano et al., 1994; De Block et al., 1998, 2003). Because of its high content of both protein and reducing sugar, and its close-to-neutral $\mathrm{pH}, \mathrm{NDM}$ is a very good medium for occurrence of the Maillard reaction (Thomas et al., 2004). The Maillard reaction is a cascade of chemical reactions occurring during the processing and storage of foods containing reducing sugars and proteins (Bourais et al., 2006). In milk products, the Maillard reaction begins with lactose condensation on proteins (lactosylation), whereas in its final stages it forms both low molecular weight degradation products (isolated Amadori compounds) and high molecular weight molecules called melanoidins (Amadori compounds polymerized, or copolymerized with proteins; Thomas et al., 2004). Jones et al. (1998) demonstrated that Maillard reaction products were formed during both the drying and ambient storage of whole milk powder. Additionally, dairy products in particular are very sensitive to light oxidation because of the presence of riboflavin (Mestdagh et al., 2005). Riboflavin is a strong photosensitizer and is able to induce a cascade of oxidation reactions, leading to significant losses of valuable nutrients, such as vitamins (including vitamins $\mathrm{A}, \mathrm{B}_{2}, \mathrm{C}, \mathrm{D}$, and $\mathrm{E}$ ) and amino acids (Borle et al., 2001). Maillard reaction and oxidation cause formation of off-flavors, color changes, and decreased nutritional value that impair product quality and marketability. Typically, Maillard reaction and oxidation are measured by chemical means. These include loss of lysine availability (Berg, 1993; Berg and van Boekel, 1994), development of Amadori product and advanced glycosylation end products (AGE; Pellegrino et al., 1995; Van Renterghem and De Block, 1996; van Boekel, 1998), and decrease in riboflavin content (Becker et al., 2003).

Fluorescence spectroscopy is a rapid, noninvasive analytical technique with high sensitivity and specificity. 
The application of fluorescence in food research has increased during the last few years with technical developments of spectrofluorometers and with the propagated application of chemometrics. Additionally, the successful introduction of front-face fluorescence spectroscopy (FFFS) to the investigation of food systems has provided a spectroscopy technique that can be used to evaluate powdered, turbid, and concentrated samples (Dufour and Riaublanc, 1997). Front-face fluorescence spectroscopy has been applied on dairy products to monitor structural changes in milk proteins during heating (Dufour and Riaublanc, 1997) and cheese manufacture (Dufour et al., 2001), oxidative changes in riboflavin (Wold et al., 2002; Becker et al., 2003) and vitamin A in yogurt and cheese (Dufour et al., 2000; Herbert et al., 2000; Andersen et al., 2005). Fluorescence spectroscopy can also be used to measure the development of Maillard reaction products in milk (Kulmyrzaev and Dufour, 2002), and a strong correlation was found between FFFS and the hydroxymethylfurfural method (Schamberger and Labuza, 2006).

The objective of this study was to determine if fluorescence spectroscopy could distinguish between NDM samples from different manufacturers and if it could be used to monitor the changes in NDM under different storage conditions. Analytical spectral properties of fluorescence were elucidated by the use of principal components analysis (PCA).

\section{MATERIALS AND METHODS}

\section{Storage of NDM}

Nine low-heat NDM samples from 3 different manufacturers ( 3 samples from each manufacturer) were collected and sealed in specimen containers and stored at 4 different temperatures $\left(4,22,35\right.$, and $50^{\circ} \mathrm{C}$, respectively). The 3 manufacturers were designated manufacturers A, B, and C. All samples were stored in the dark, being exposed occasionally to light during sampling. The powders were sampled for analysis before storage and after 1, 2, 4, and 8 wk of storage. The protein, moisture, fat, solubility, scorched particles, and whey protein nitrogen index were determined as described in the Standards for Grades of Dry Milk (American Dairy Products Institute, 1990).

\section{Color Measurement}

Samples were analyzed for 3 color indices, $L^{*}$ (white to black), $a^{*}$ (red to green), and $b^{*}$ (yellow to blue) using a Hunterlab colorimeter (Minolta Corp., Ramsey, NJ). Each color value reported was the mean of 3 determinations.

\section{FFFS}

Each NDM sample was loaded into a powder cell fitted with a quartz window. The cell was then mounted on a front face accessory fitted to a Perkin-Elmer LS50B spectrometer (Perkin-Elmer, Beaconsfield, UK, such that the incidence angle of excitation onto the cell was $56^{\circ}$. The fluorescence spectrum from each powder was obtained using FLDM software (Perkin-Elmer). Six scans were performed on each sample to record the emission spectra of Maillard products (380 to $480 \mathrm{~nm}$ ) at an excitation wavelength of $360 \mathrm{~nm}$, the emission spectra of tryptophan (305 to $450 \mathrm{~nm}$ ) at an excitation wavelength of $290 \mathrm{~nm}$, the emission spectrum of riboflavin (400 to $590 \mathrm{~nm}$ ) at an excitation of $380 \mathrm{~nm}$, and the excitation spectrum in the 260 to $350 \mathrm{~nm}$ range at an emission of $410 \mathrm{~nm}$. The slit widths were set at 9.0 and $4.0 \mathrm{~nm}$ for excitation and emission, respectively, and a $2 \%$ attenuation filter was used at the excitation slit. Each NDM sample was analyzed 3 times. Consequently, a total of 18 individual spectra were collected at each temperature at each storage time for each sample.

\section{Data Analysis}

Before multivariate analysis of the spectral data, all 18 of the spectral scans from each sample at each temperature at each storage time were averaged. Subsequently, the averaged spectra were normalized by reducing the area under each curve to unity as described by Bertrand and Scotter (1992) and mean centered such that the average of all the spectra was subtracted from each spectrum. The spectral data were then analyzed using PCA. This multivariate approach was utilized to identify the main systematic variation in the data, which is extracted into principal components (PC). In this analysis, the data were decomposed into a score matrix and a loading matrix. All the analysis was carried out using GRAMS 32AI (Galactic Industries Corp., Salem, NH).

\section{RESULTS AND DISCUSSION}

\section{Composition and Physical Properties of NDM}

The composition and physical properties of each sample are shown in Table 1. All NDM samples met the US grading requirements for nonfat dry milk. The protein, fat, and moisture contents ranged from 34.7 to $35.6 \%, 0.7$ to $0.9 \%$, and 3.1 to $4.0 \%$, respectively.

\section{Color Measurement}

The mean $L^{*}, a^{*}$, and $b^{*}$ values of the 9 samples before storage and after $8 \mathrm{wk}$ of storage at $50^{\circ} \mathrm{C}$ are 
LIU AND METZGER

Table 1. Composition and physical properties of low-heat NDM samples collected from 3 manufacturers

\begin{tabular}{llllllll}
\hline Manufacturer & Sample & $\begin{array}{l}\text { Moisture } \\
(\%)\end{array}$ & $\begin{array}{l}\text { Fat } \\
(\%)\end{array}$ & $\begin{array}{l}\text { Protein } \\
(\%)\end{array}$ & Solubility & $\begin{array}{l}\text { Scorched } \\
\text { particles }\end{array}$ & $\begin{array}{l}\text { Whey } \\
\text { protein N }\end{array}$ \\
\hline A & A1 & 4.0 & 0.7 & 35.6 & 0.1 & 7.5 & 8.0 \\
A & A2 & 3.9 & 0.9 & 35.4 & 0.2 & 7.5 & 7.6 \\
A & A3 & 3.8 & 0.7 & 35.6 & 0.1 & 7.5 & 7.4 \\
B & B1 & 3.2 & 0.7 & 34.8 & 0.1 & 7.5 & 7.8 \\
B & B2 & 3.1 & 0.7 & 34.8 & 0.1 & 7.5 & 7.8 \\
B & B3 & 3.1 & 0.7 & 34.7 & 0.1 & 7.5 & 7.5 \\
C & C1 & 3.4 & 0.8 & 35.3 & 0.1 & 7.5 & 7.1 \\
C & C2 & 3.5 & 0.8 & 35.4 & 0.1 & 7.5 & 7.1 \\
C & C3 & 3.5 & 0.7 & 34.7 & 0.1 & 7.5 & \\
\hline
\end{tabular}

shown in Table 2. No color differences were observed from the NDM samples stored at 4,22 , and $35^{\circ} \mathrm{C}$ (data not shown), whereas a decrease in $\mathrm{L}^{*}$ value (whiteness), and increases in $\mathrm{a}^{*}$ (redness) and $\mathrm{b}^{*}$ values (yellowness) were observed after $8 \mathrm{wk}$ of storage at $50^{\circ} \mathrm{C}$. The results indicated a decrease in the whiteness and increases in red and yellow color components.

\section{FFFS}

Fluorescence Spectra of NDM Samples Before Storage. Figure 1 shows an overlaid view of the averaged and unit area normalized emission fluorescence spectra for Maillard reaction products (Figure 1a), excitation spectrum in the 260 to $350 \mathrm{~nm}$ range (emission $410 \mathrm{~nm}$; Figure 1b), and emission spectra for tryptophan (Figure 1c) and riboflavin (Figure 1d) from the NDM samples before storage. The NDM samples from different manufacturers displayed similar characteristics in the individual spectra, with only minor variations in the shapes of the spectra.

The Maillard emission spectrum showed a broad peak with emission maximum around $423 \mathrm{~nm}$ (Figure 1a). It has been reported that the AGE have a maximum emission wavelength between 420 and $450 \mathrm{~nm}$ (Christensen et al., 2003; Matiacevich and Buera, 2006); thus, the peak at $423 \mathrm{~nm}$ may correspond to advanced Maillard reaction products. The excitation spectrum in the 260 to $350 \mathrm{~nm}$ range showed a peak around $340 \mathrm{~nm}$ (Figure 1b). Fluorescent products (excitation and emission wavelengths of 347 and $415 \mathrm{~nm}$ ) have been observed in milk and milk-resembling systems during the Maillard reaction (Morales et al., 1996; Birlouez-Aragon et al., 2002), which is consistent with our observation. Although this region has been used to study the characteristics of vitamin A as well, our samples contained less than $1 \%$ fat; the characteristic peak of vitamin A (fat-soluble) at $322 \mathrm{~nm}$ (Dufour and Riaublanc, 1997) was not observed in our spectra. Thus, the excitation spectra in the present study can be attributed to the presence of Maillard reaction products in the NDM samples, and the excitation spectrum in the 260- to $350-\mathrm{nm}$ range (emission $410 \mathrm{~nm}$ ) is referred to as the Maillard excitation spectrum in this study.

The tryptophan emission spectra (Figure 1c) presented a typical tryptophan maximum located around $338 \mathrm{~nm}$. The prominent peak around $510 \mathrm{~nm}$ in the riboflavin emission spectra (Figure 1d) was attributed to the presence of riboflavin (Wold et al., 2002; Becker et al., 2003).

PCA of Fluorescence Spectra of NDM Samples Before Storage. The Maillard products excitation and

Table 2. Mean values of $\mathrm{L}^{*}$, $\mathrm{a}^{*}$, and $\mathrm{b}^{*}$ for the NDM samples before storage and samples stored at $50^{\circ} \mathrm{C}$ for $8 \mathrm{wk}^{1}$

\begin{tabular}{|c|c|c|c|c|c|c|}
\hline \multirow[b]{2}{*}{ Sample } & \multicolumn{3}{|c|}{ Before storage } & \multicolumn{3}{|c|}{ Stored at $50^{\circ} \mathrm{C}$ for $8 \mathrm{wk}$} \\
\hline & $\mathrm{L}^{*}$ & $a^{*}$ & $\mathrm{~b}^{*}$ & $\mathrm{~L}^{*}$ & $a^{*}$ & $\mathrm{~b}^{*}$ \\
\hline $\mathrm{A} 1$ & 98.54 & -3.73 & 10.44 & 97.39 & -3.65 & 11.45 \\
\hline A2 & 99.39 & -3.78 & 10.10 & 97.44 & -3.69 & 11.46 \\
\hline A3 & 98.74 & -4.20 & 11.11 & 97.30 & -3.83 & 12.01 \\
\hline B1 & 99.00 & -3.90 & 9.93 & 97.13 & -3.65 & 11.35 \\
\hline B2 & 98.99 & -3.85 & 10.02 & 97.76 & -3.57 & 10.91 \\
\hline B3 & 99.53 & -3.93 & 9.69 & 97.54 & -3.76 & 11.00 \\
\hline C1 & 99.51 & -4.15 & 10.70 & 97.75 & -3.84 & 11.61 \\
\hline C2 & 99.07 & -3.93 & 10.50 & 97.60 & -3.67 & 11.30 \\
\hline C3 & 99.50 & -3.68 & 9.72 & 97.71 & -3.55 & 10.94 \\
\hline
\end{tabular}

${ }^{1} L^{*}, a^{*}, b^{*}$ color system: $L^{*}(0=$ black; 100 = white component $) ; a^{*}(+=$ red; - = green component $)$; and $\mathrm{b}^{*}$ (+ = yellow; $-=$ blue component). 

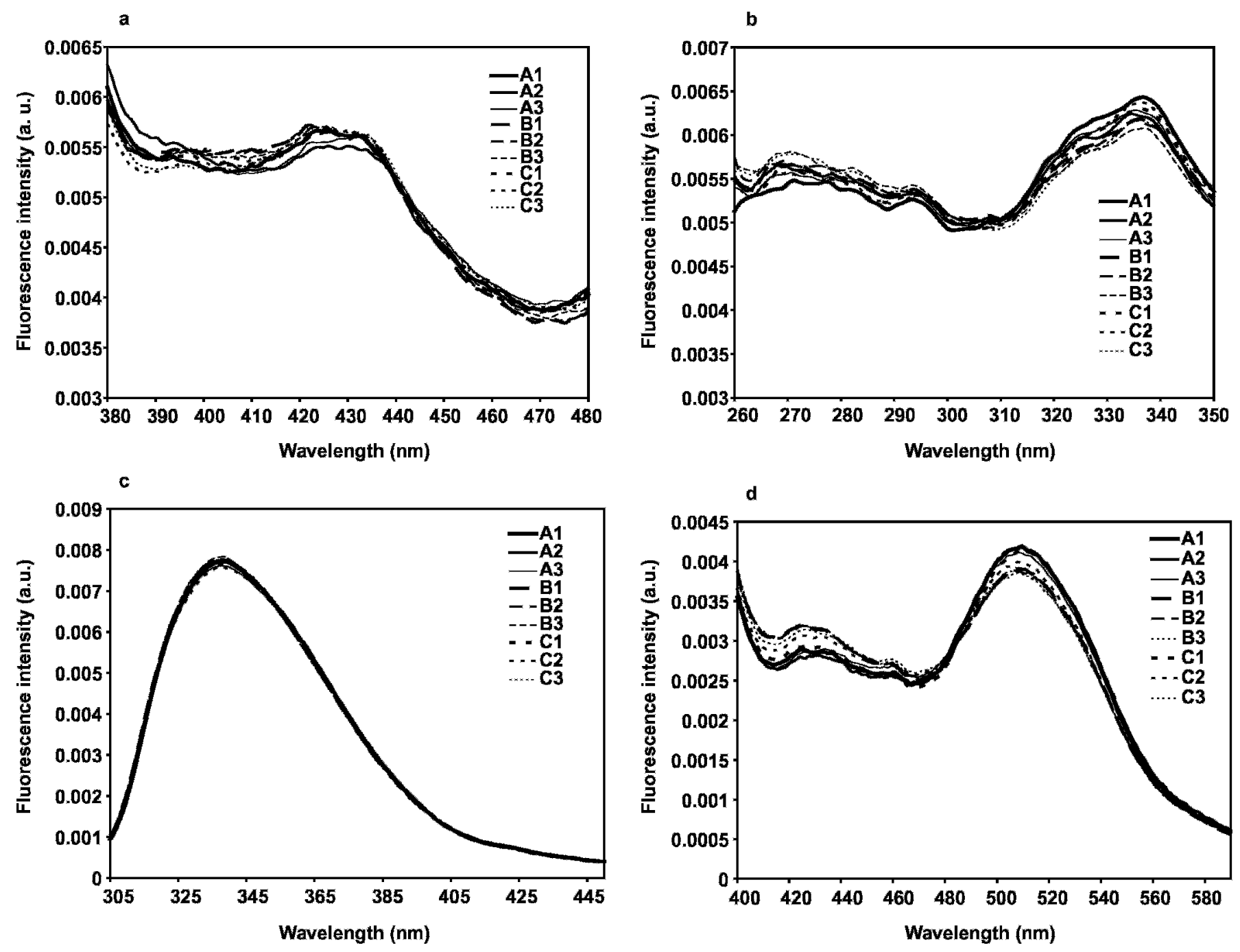

Figure 1. Maillard emission (a), Maillard excitation (b), tryptophan emission (c), and riboflavin emission (d) spectra of the NDM samples before storage. The curves represent 3 samples each (1, 2, and 3) from each of 3 manufacturers (A, B, and C).

emission spectra, tryptophan emission spectra, and riboflavin emission spectra of the 9 samples before storage were processed before PCA as discussed earlier. The results of PCA (factor loadings and score plots) applied to the averaged and normalized FFFS spectra of the NDM samples before storage are presented in Figures 2 through 5.

For the Maillard emission spectra, the characteristics of $92 \%$ of the data were described by the first 2 components. The factor loadings plot of PC1 showed a broad band around $420 \mathrm{~nm}$, and the factor loadings of PC2 presented an opposition between a negative band at 380 to $400 \mathrm{~nm}$ and a positive broad band between 450 and $480 \mathrm{~nm}$ (Figure 2a). Moreaux and Birlouez-Aragon (1997) reported that intense Maillard reaction of $\beta$-LG and lactose generated $2 \mathrm{AGE}$, with maximum emission at $425 \mathrm{~nm}$ and 450 to $460 \mathrm{~nm}$, respectively. Kulmyrzaev and Dufour (2002) observed a shift in the maximum emission wavelength from $416 \mathrm{~nm}$ to $429 \mathrm{~nm}$ after excessive heat treatment of the milk. Therefore, PC1 and PC2 may describe the presence and variation in the AGE in the NDM samples before storage. Advanced glycosylation end products include a very complex combination of products, only a few of which have been elucidated. Although excitation at 340 to $370 \mathrm{~nm}$ and emission at 410 to $440 \mathrm{~nm}$ is widely used for the measurement of AGE (Moreaux and Birlouez-Aragon, 1997; Ferrer et al., 2005; Matiacevich and Buera, 2006), the identification of the corresponding fluorescent products (PC1 in our case) is still unclear. Among the identified AGE in dairy products, pentosidine is a fluorescent molecule with a maximum emission at $385 \mathrm{~nm}$ and origi- 

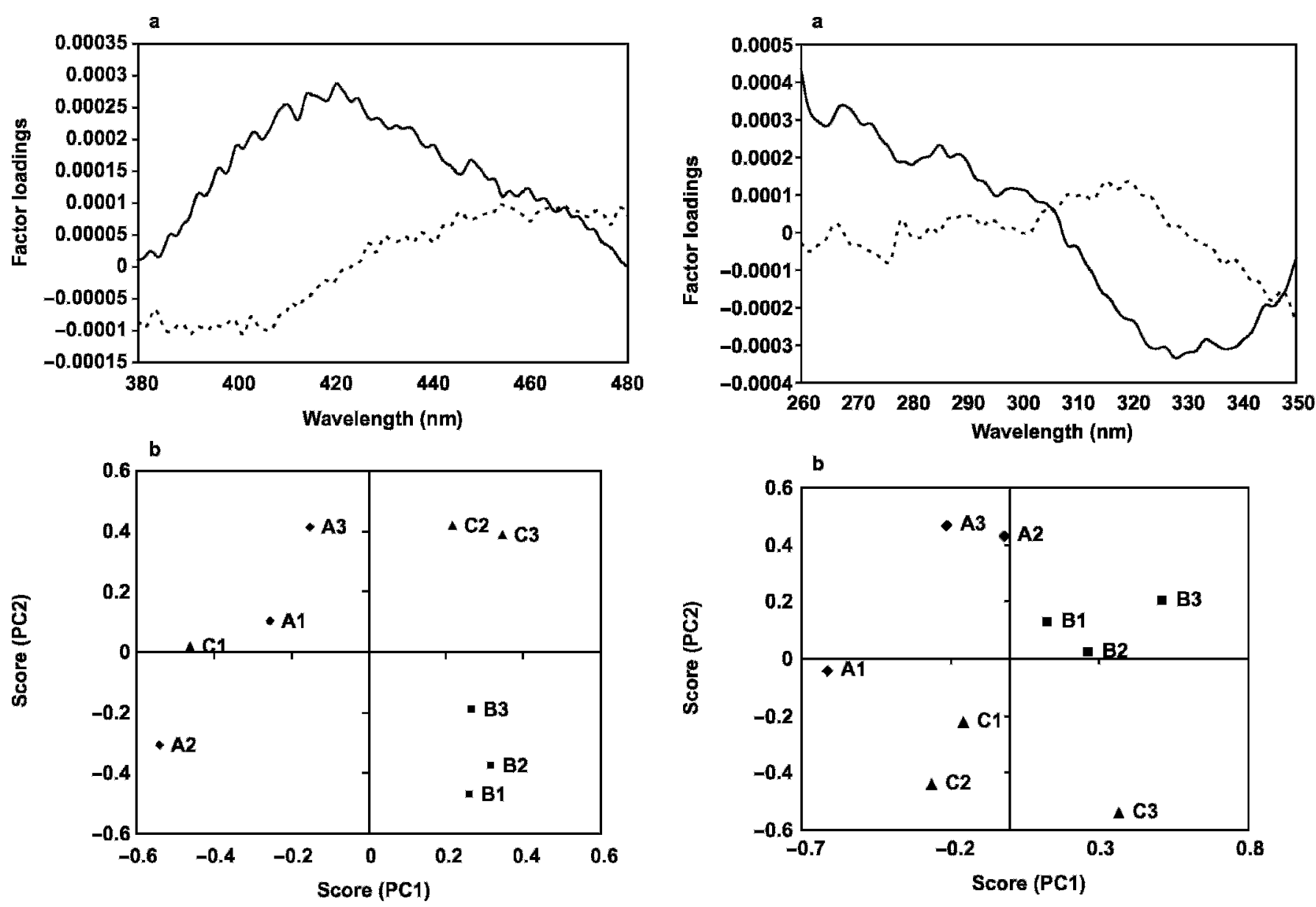

Figure 2. Factor loadings of the first 2 principal components (a) and similarity map (b) of principal component analysis (PCA) made on Maillard emission spectra of the NDM samples before storage. The lines in (a) indicate: PC1 (solid) and PC2 (dotted). The symbols in (b) represent the 9 samples collected from manufacturer A $(\diamond), \mathrm{B}$ (ם) and $\mathrm{C}(\boldsymbol{\Delta})$ (3 from each manufacturer).

nates from decomposition of the Amadori product, 3deoxyosone pathway (Ferrer et al., 2005). Siegl et al. (2000) reported that an increase in fluorescence intensity at $463 \mathrm{~nm}$ was related to the formation of the crosslinked products. Therefore, PC2 may describe the contents of pentosidine and cross-linked compounds in the samples, and it appears that an increase in the formation of cross-linked compounds is accompanied by a decrease in the amount of pentosidine.

Differences in the FFFS Maillard emission spectra of the NDM samples collected from different manufacturers were observed (Figure $2 \mathrm{~b}$ ). The 3 NDM samples collected from manufacturer A all had negative PC1 scores, but variation in PC2 scores was observed between these samples, with A3 having the highest value and A2 having the lowest value. The NDM samples collected from manufacturer $\mathrm{B}$ displayed consistent

Figure 3. Factor loadings of the first 2 principal components (a) and similarity map (b) of principal component analysis (PCA) made on Maillard excitation spectra of the NDM samples before storage. The lines in (a) indicate: PC1 (solid) and PC2 (dotted). The symbols in (b) represent the 9 samples collected from manufacturer A ( ), B

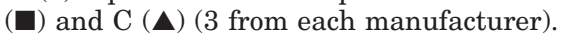

characteristics because they clustered together in the plot, with positive PC1 scores and negative PC2 scores. Variation was observed for the samples from manufacturer C. Two of the samples collected from manufacturer $\mathrm{C}$ (C2 and $\mathrm{C} 3)$ had positive $\mathrm{PC} 1$ and $\mathrm{PC} 2$ scores, with the other $(\mathrm{C} 1)$ having a negative PC1 score and a close-to-zero PC2 score. Clearly, samples from different manufacturers showed different characteristics in the FFFS Maillard emission spectra, indicating that variation in the types and amounts of Maillard reaction products accumulated during their manufacturing processes. Other researchers (Guyomarc'h et al., 2000) have reported that spray-drying conditions can influence the level of the Maillard reaction that occurs in NDM as measured by the amount of lactosylation of milk proteins. In addition to the spray-drying process, pasteurization and preheat treatments may also influ- 

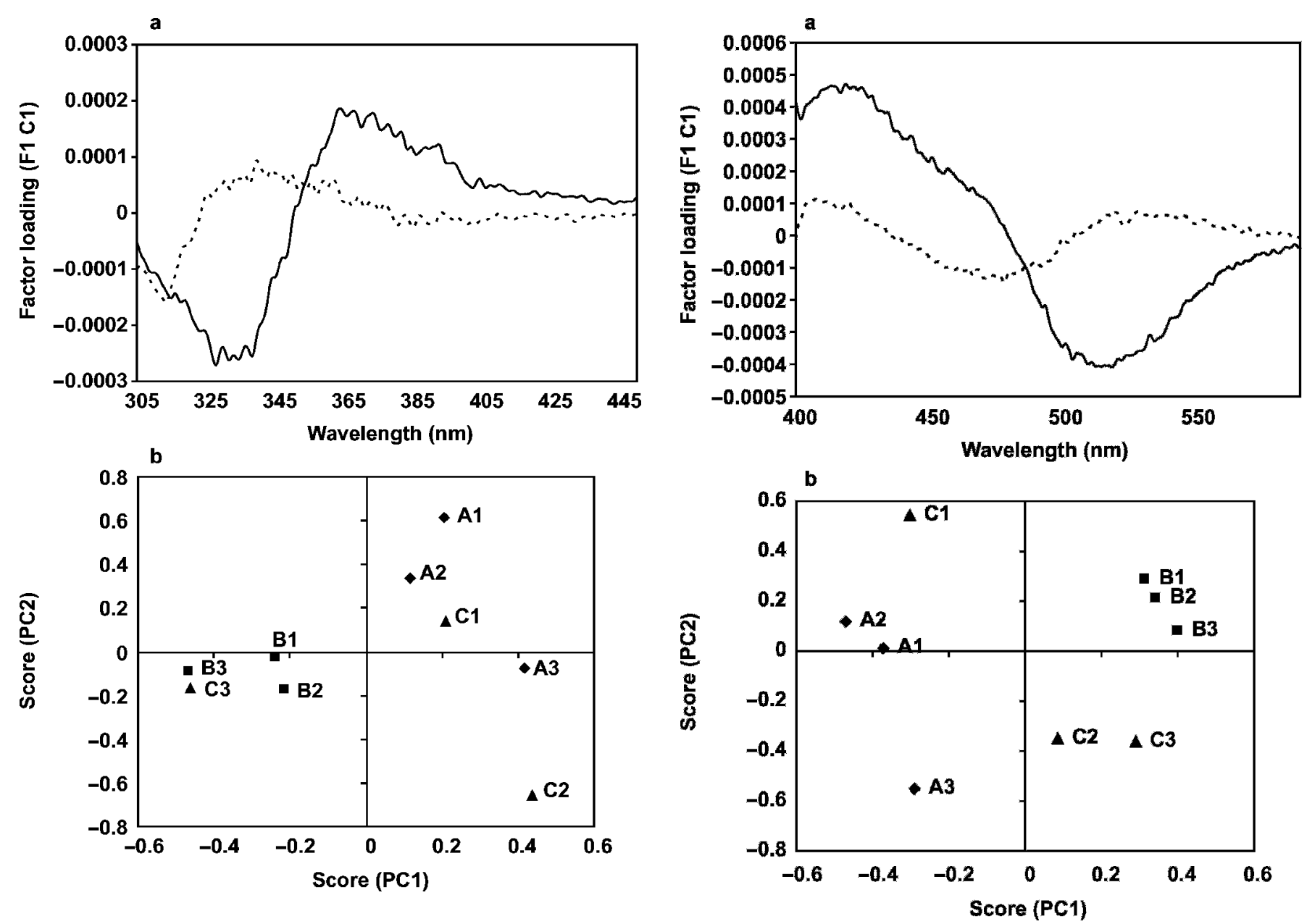

Figure 4. Factor loadings of the first 2 principal components (a) and similarity map (b) of principal component analysis (PCA) made on tryptophan emission spectra of the NDM samples before storage. The lines in (a) indicate: PC1 (solid) and PC2 (dotted). The symbols in (b) represent the 9 samples collected from manufacturer A $(\diamond), \mathrm{B}$ (ם) and C ( $\mathbf{\Delta})$ (3 from each manufacturer).

ence the FFFS Maillard emission spectra. Because the samples from manufacturer B had the most consistent FFFS Maillard emission spectra, they may also have the most consistent NDM production process.

For the Maillard excitation spectra, the characteristics of $96 \%$ of the data were described by the first 2 components. In Figure 3a, the factor loadings of PC1 of Maillard excitation data presented an opposition between a positive band from 268 to $295 \mathrm{~nm}$ and a negative band between 320 and $340 \mathrm{~nm}$. Leclére and Birlouez-Aragon (2001) developed a fluorimetric method to estimate the heat treatment of milk by measuring the advanced Maillard products (AMP) at 330 to 420 $\mathrm{nm}$. They reported that AMP fluorescence increased during heat treatment at $60^{\circ} \mathrm{C}$ (Leclére and BirlouezAragon, 2001). Therefore, PC1 may describe the amount of AMP in the samples, resulting from the vari-

Figure 5. Factor loadings of the first 2 principal components (a) and similarity map (b) of principal component analysis (PCA) made on riboflavin emission spectra of the NDM samples before storage. The lines in (a) indicate: PC1 (solid) and PC2 (dotted). The symbols in (b) represent the 9 samples collected from manufacturer A ( $\bullet$ ), B $(\boldsymbol{\square})$ and $\mathrm{C}(\boldsymbol{\Delta})$ (3 from each manufacturer).

ation in production processes between the manufacturers. The factor loadings plot for PC2 showed a broad band at about $320 \mathrm{~nm}$ (Figure 3a). Principal component 2 may describe the changes in the shape of the Maillard excitation spectra in the NDM samples. As was the case for the Maillard emission similarity map, the samples from different manufacturers showed different characteristics in the plot (Figure 3b). However, no similar patterns were observed from the Maillard emission and excitation similarity maps, which suggested that the Maillard emission and excitation spectra might describe the presence of different Maillard reaction products.

The factor loading plots corresponding to PC1 and PC2, and the similarity maps for tryptophan and riboflavin emission fluorescence data are shown in Figure 
4 and 5, respectively. The first $2 \mathrm{PC}$ took into account 94\% (tryptophan data) and 99\% (riboflavin data) of the total variability.

For the tryptophan spectra, the factor loadings of PC1 showed opposition between a negative peak at 335 $\mathrm{nm}$ and a positive one at $365 \mathrm{~nm}$ (Figure 4a), which indicated changes in the shape of the spectra and tryptophan maximum emission wavelength. Samples with positive PC1 scores in Figure 4b had a broader peak than the samples with negative PC1 scores. Variation in the tryptophan maximum emission wavelength was also observed among the samples. Samples B1 and C1 had the shortest tryptophan maximum emission wavelength at $336.5 \mathrm{~nm}$, and A2 showed the longest wavelength at $338.5 \mathrm{~nm}$. It is known that changes in tryptophan maximum emission wavelength indicate changes in the polarity of tryptophan residues' microenvironment (Liu et al., 2005). Therefore, variation in the hydrophobicity of the tryptophan residues in the NDM samples before storage was found among the samples. The factor loading 2 exhibited a positive maximum around $340 \mathrm{~nm}$ (Figure 4a), suggesting that the spectral peak of some samples was somewhat larger than the others. Dufour and Riaublanc (1997) compared the FFFS tryptophan spectra of raw and heated milks and reported that discriminations of the samples can be realized as a function of heat treatment. Thus, the variation in the tryptophan spectra observed in our study was probably due to the variation in the manufacturing conditions of the NDM samples, such as pasteurization and spray-drying conditions. As was the case with the FFFS Maillard products spectra, the FFFS tryptophan spectra for NDM samples from manufacturer B showed good consistency and clustered together on the left of the similarity map (Figure $4 \mathrm{~b}$ ). All 3 samples from manufacturer $\mathrm{A}$ and 2 samples from manufacturer $\mathrm{C}$ (C1 and C2) displayed positive PC1 scores. The other sample from manufacturer $\mathrm{C}(\mathrm{C} 3)$ had a negative $\mathrm{PC} 1$ score and similar characteristics as the samples from manufacturer B.

For the riboflavin data, the factor loadings of PC1 presented an opposition between a positive peak at 420 $\mathrm{nm}$ and a negative peak at $515 \mathrm{~nm}$ (Figure 5a). Fluorescent oxidation products produced by the reaction between amino groups and aldehydes exhibit fluorescence with emission maxima at 400 to $470 \mathrm{~nm}$ (Dillard and Tappel, 1971; Kikugawa and Beppu, 1987), whereas riboflavin has an emission maximum around $520 \mathrm{~nm}$ (Skibsted, 2000). Thus, PC1 may correspond to the amount of riboflavin and oxidation products in the samples. The factor loadings for PC2 showed an opposition between a positive peak at $410 \mathrm{~nm}$ and a negative one at $480 \mathrm{~nm}$ (Figure 5a). It has been reported that the degradation of riboflavin led to the formation of lumi- chrome, which has a maximum emission in the range of 444 to $479 \mathrm{~nm}$ (Fox and Thayer, 1998). Therefore, PC2 may represent the formation of lumichrome in the samples. A discrimination of the samples before storage based on the riboflavin data was observed according to the PCA similarity map defined by PC1 and PC2 (Figure $5 b)$. The NDM samples collected from manufacturer A and B showed consistent characteristics among them, with negative and positive PC1 scores, respectively. Inconsistency was observed again for the samples collected from manufacturer C. Sample $\mathrm{C} 1 \mathrm{had}$ a negative PC1 score and positive PC2 score, whereas samples $\mathrm{C} 2$ and $\mathrm{C} 3$ showed positive PC1 scores and negative PC2 scores.

Overall, the most consistency was observed in the samples collected from manufacturer B in the PCA for Maillard, tryptophan, and riboflavin data, which again may indicate better control in their manufacturing process compared with the other 2 manufacturers.

When comparing the 4 similarity maps for Maillard, tryptophan, and riboflavin spectra, some commonality was observed between the Maillard emission and riboflavin fluorescence data. The NDM samples with positive scores of PC1 in the Maillard emission plot (B1, B2, B3, C2, and C3) all showed positive scores of PC1 in the riboflavin plot. The NDM samples with negative scores of PC1 in the Maillard emission plot (A1, A2, $\mathrm{A} 3$, and $\mathrm{C} 1$ ) all showed negative scores of PC1 in the riboflavin plot. On the other hand, negative scores of PC2 in the Maillard emission plot and positive scores of PC2 in the riboflavin plot were observed, and vice versa. It indicates that a decrease in the amount of riboflavin is accompanied by the formation of oxidation products and AGE, whereas formation of cross-linked Maillard products occurs together with formation of lumichrone (one of the degradation products of riboflavin). Because the excitation wavelengths for the Maillard products and riboflavin are very close to each other (360 $\mathrm{nm}$ for Maillard and $380 \mathrm{~nm}$ for riboflavin scan), it is possible to perform one scan for both the Maillard product and riboflavin with a broader emission wavelength region from 400 to $600 \mathrm{~nm}$. Thus, the Maillardriboflavin emission spectrum can provide us with information not only on the presence of the Maillard reactions products, but also on the oxidation of riboflavin.

Spectra Changes of NDM Samples During Storage. Changes in the spectra were observed during storage for the NDM samples, especially for the samples stored at $50^{\circ} \mathrm{C}$. An overlaid view of the averaged and unit area normalized spectra for sample A1 (stored at $50^{\circ} \mathrm{C}$ for $0,1,2,4$, and $8 \mathrm{wk}$ ) is shown in Figure 6 as an example. The other samples displayed similar patterns of changes during storage. For the Maillard emission spectra, increases in the peak intensity be- 


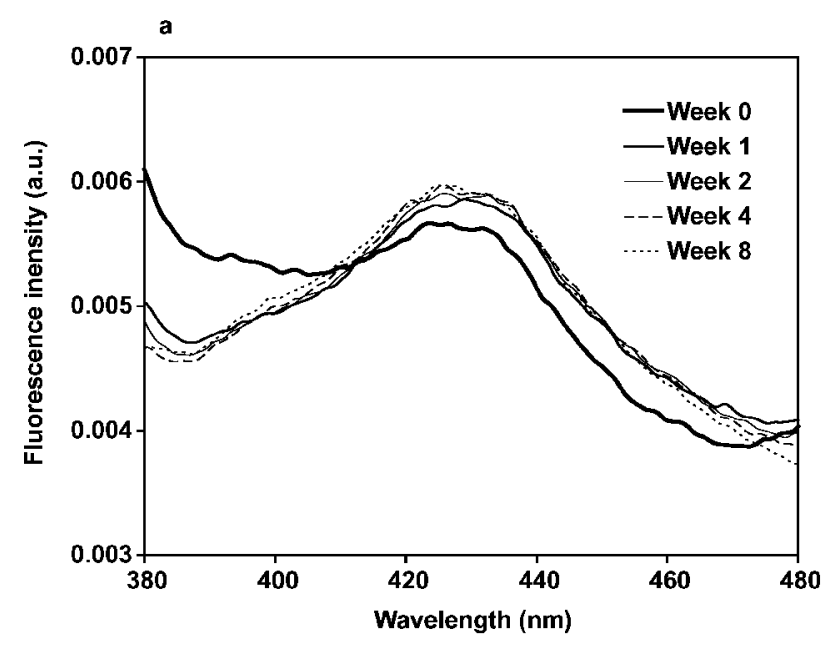

b
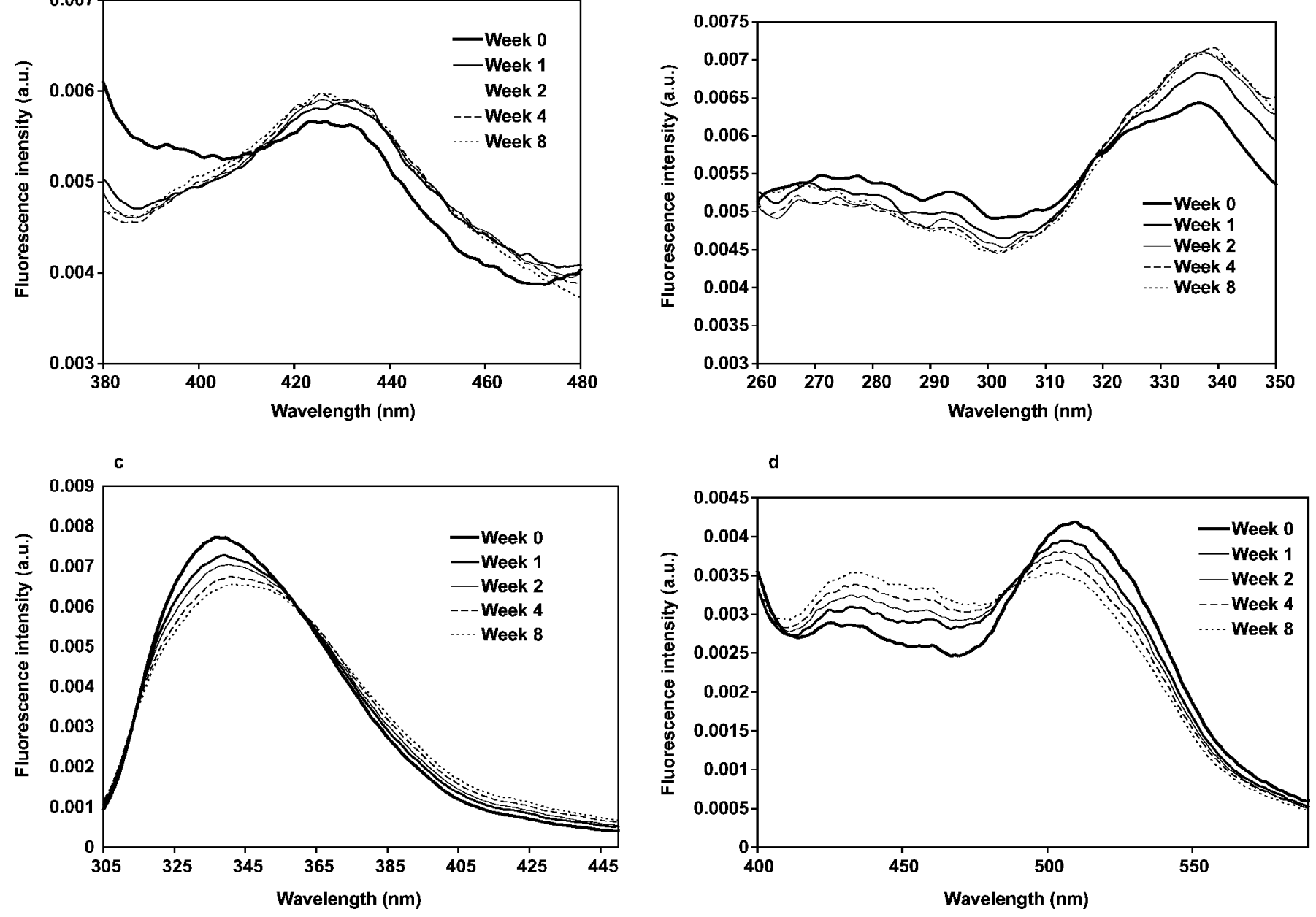

Figure 6. Fluorescence spectra of NDM samples before storage and samples stored at $50^{\circ} \mathrm{C}$ for 1,2 , 4 , and 8 wk. (a) Maillard emission spectra, (b) Maillard excitation spectra, (c) tryptophan emission spectra, (d) riboflavin emission spectra.

tween 410 and $440 \mathrm{~nm}$ were observed, which may be due to the increases in the formation of the advanced Maillard reaction products during storage (Figure 6a). Storage at $50^{\circ} \mathrm{C}$ resulted in increases in the peak intensity around $337 \mathrm{~nm}$ in the Maillard excitation spectra (Figure 6b), which confirmed the formation of Maillard reaction products during storage at $50^{\circ} \mathrm{C}$ in NDM.

Decreases in peak intensity as well as red shifts were found in the tryptophan emission spectra (Figure 6c), which indicated changes in the environment of the tryptophan residues in dairy proteins during storage. Decreases in the peak intensity at $515 \mathrm{~nm}$ and increases in the peak intensity between 410 and $480 \mathrm{~nm}$ were observed in the riboflavin spectra (Figure $6 \mathrm{~d}$ ), and the degradation of riboflavin may be responsible for these changes.

PCA Results of NDM Samples During Storage. Principal components analysis was applied separately on the 4 collections of normalized spectra corresponding to Maillard emission and excitation fluorescence, tryptophan emission fluorescence, and riboflavin emission. The similarity maps and the factor loadings of the first 2 PC of the 4 fluorescence data sets are presented in Figures 7 through 10. The first PC accounted for 89\% (Maillard emission data), 92\% (Maillard excitation data), $94 \%$ (tryptophan data), and 85\% (riboflavin data) of the total variability. The second $\mathrm{PC}$ accounted for 9\% (Maillard emission data), 5\% (Maillard excitation data), $5 \%$ (tryptophan data), and $14 \%$ (riboflavin data) of the total variability.

For each of the 4 data collections, discrimination of the NDM samples stored at $50^{\circ} \mathrm{C}$ from the other samples stored at 4,22 , and $35^{\circ} \mathrm{C}$ was observed in the similarity maps. In the PCA results of Maillard emission fluorescence (Figure 7a), most of the NDM samples stored at 4,22 , and $35^{\circ} \mathrm{C}$ had positive $\mathrm{PC} 1$ scores, 

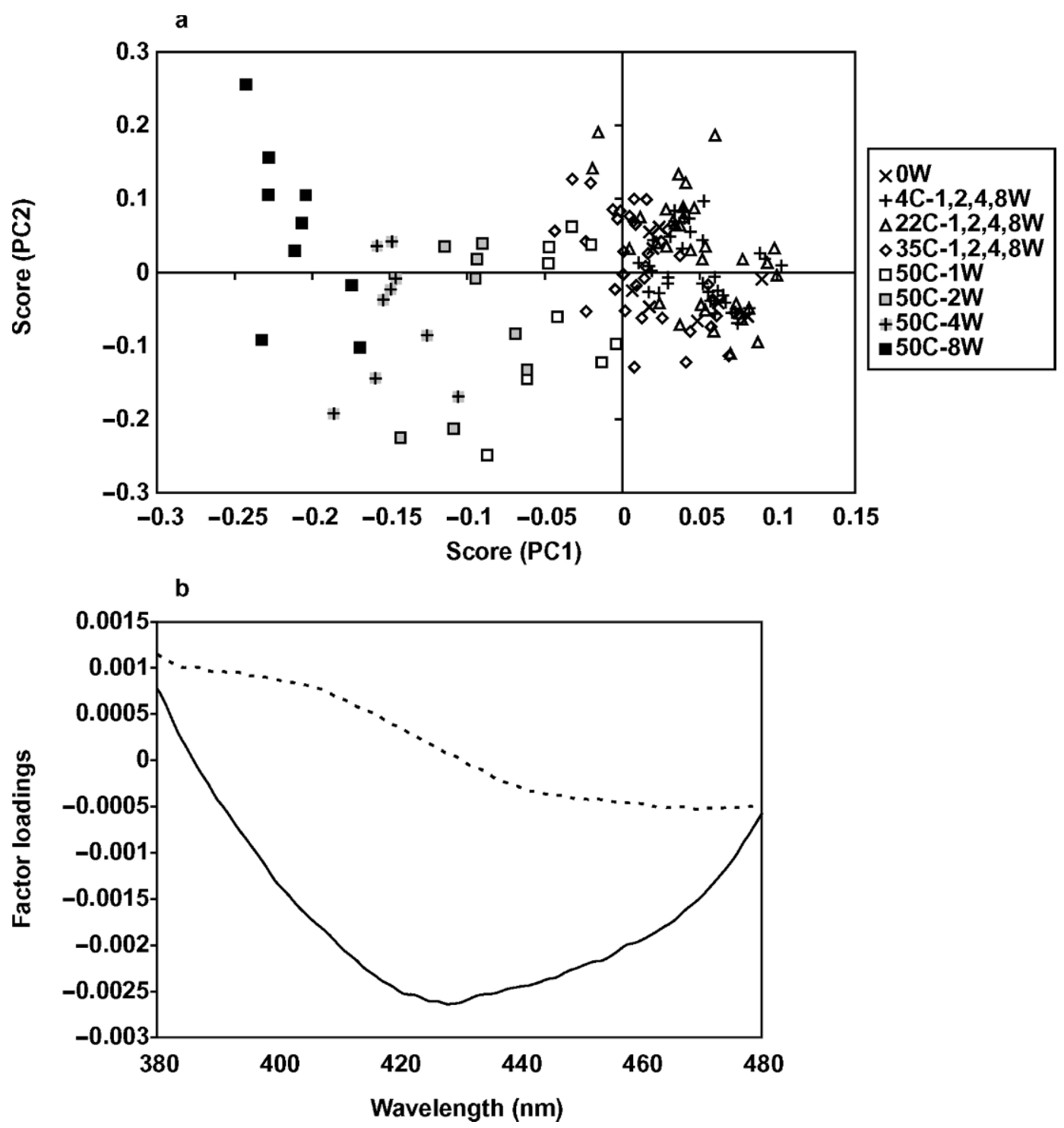

Figure 7. Principal component analysis (PCA) made on Maillard emission spectra of the NDM samples: (a) Similarity map of the NDM samples before storage and after storage at $4,22,35$, and $50^{\circ} \mathrm{C}(\mathrm{C}$ in key) for $1,2,4$, and 8 wk (W in key); (b) factor loadings of the first 2 principal components; the lines in (b) indicate: PC1 (solid) and PC2 (dotted).

whereas all the samples stored at $50^{\circ} \mathrm{C}$ had negative scores in PC1. A continuous decrease in the PC1 scores was observed for each sample during storage at $50^{\circ} \mathrm{C}$, regardless of manufacturer. The factor loadings for PC1 showed a prominent peak around $430 \mathrm{~nm}$ as a result of the accumulation of AGE in all the NDM samples during storage at $50^{\circ} \mathrm{C}$ (Figure $7 \mathrm{~b}$ ). The factor loadings of PC2 showed an opposition between a positive band between 380 and $400 \mathrm{~nm}$ and a negative band between 460 and $480 \mathrm{~nm}$ (Figure 7b), similar to the factor loadings plot of the samples before storage. Thus, PC2 may describe the contents of pentosidine and cross-linked compounds in the samples as was discussed earlier in the PCA analysis for the NDM samples before storage. After the comparison with the PCA results for the Maillard fluorescence spectra of the samples before storage, we noticed similarity between the factor loadings of the first $2 \mathrm{PC}$ of the 2 sets of data. It appears that similar factors (various types and amounts of Maillard reaction products) are responsible for the variation in the samples before storage and their changes during storage.

The similarity map of the Maillard excitation data showed a different pattern than that of the Maillard emission data. The storage of the samples at $50^{\circ} \mathrm{C}$ resulted in increases in the PC1 scores up to $4 \mathrm{wk}$ (Figure $8 a)$. After that, further storage at $50^{\circ} \mathrm{C}$ only caused 
a

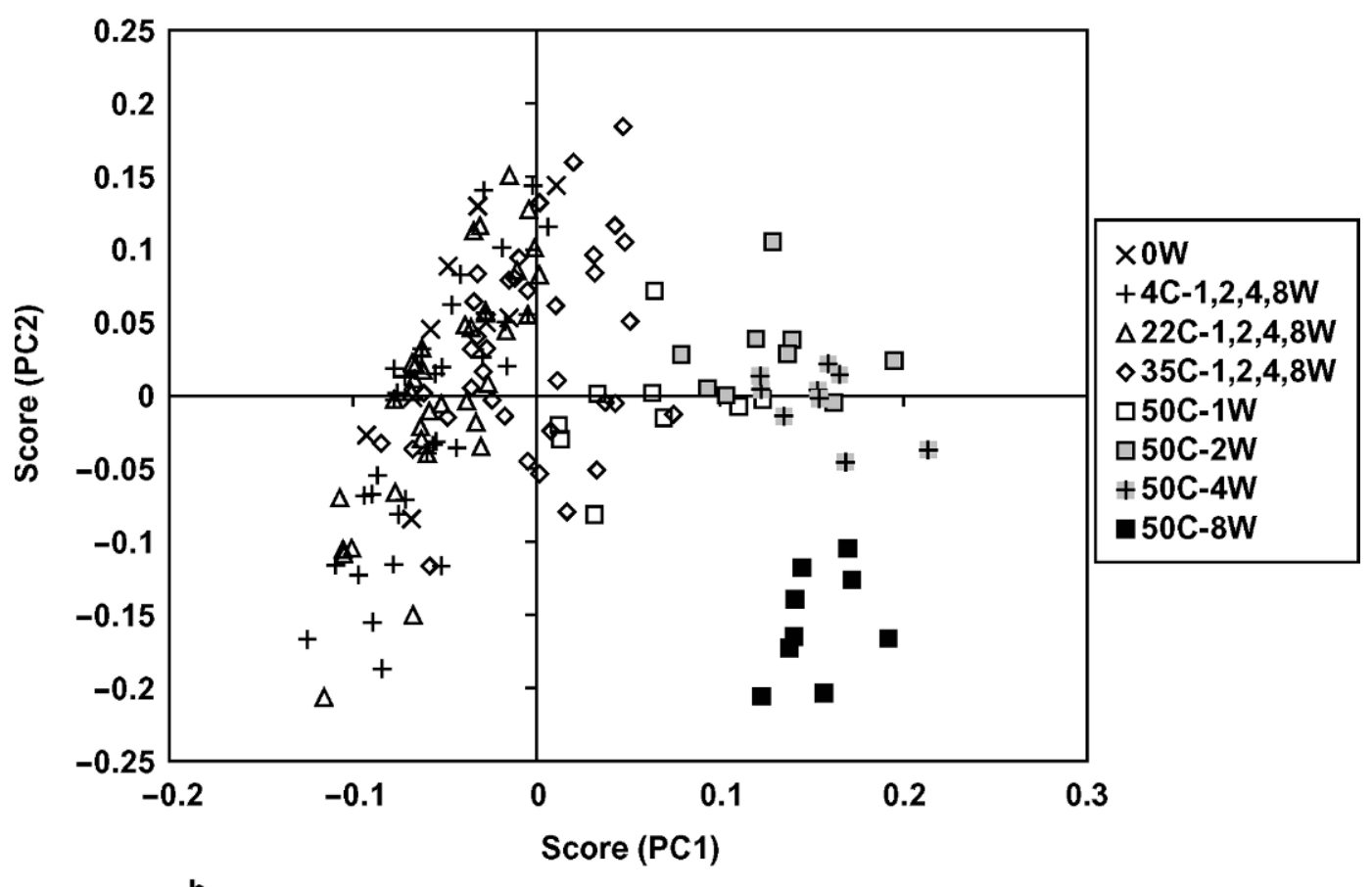

b

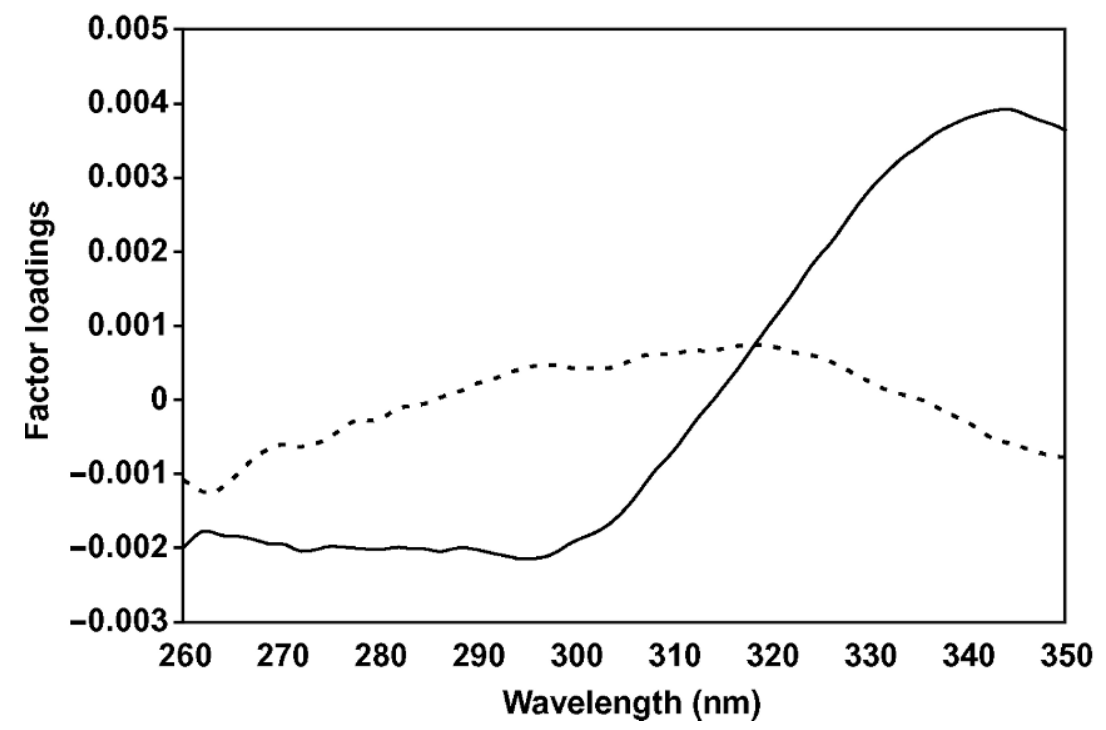

Figure 8. Principal component analysis (PCA) made on Maillard excitation spectra of the NDM samples: (a) Similarity map of the NDM samples before storage and after storage at 4,22, 35, and $50^{\circ} \mathrm{C}(\mathrm{C}$ in key) for $1,2,4$, and 8 wk (W in key); (b) factor loadings of the first 2 principal components; the lines in (b) indicate: PC1 (solid) and PC2 (dotted).

increases in the PC2 scores in the samples. In Figure $8 \mathrm{~b}$, the factor loadings of the first PC presented an opposition between a negative band between 260 and $300 \mathrm{~nm}$ and a positive peak at $340 \mathrm{~nm}$. Although the identifications of these compounds were not clear, it seemed that these Maillard reaction products were not the same ones characterized by the Maillard emission data. The factor loading of PC2 showed a broad peak covering the whole region, which indicated changes in the fluorescence intensity of the spectra.

In the tryptophan similarity map (Figure 9a), storage at $50^{\circ} \mathrm{C}$ gave these samples larger PC1 scores than the samples stored at the other temperatures. The factor loadings of PC1 showed an opposition between a negative peak at $335 \mathrm{~nm}$ and a positive one at 370 $\mathrm{nm}$ (Figure 9b), and the factor loading 2 exhibited a 
a

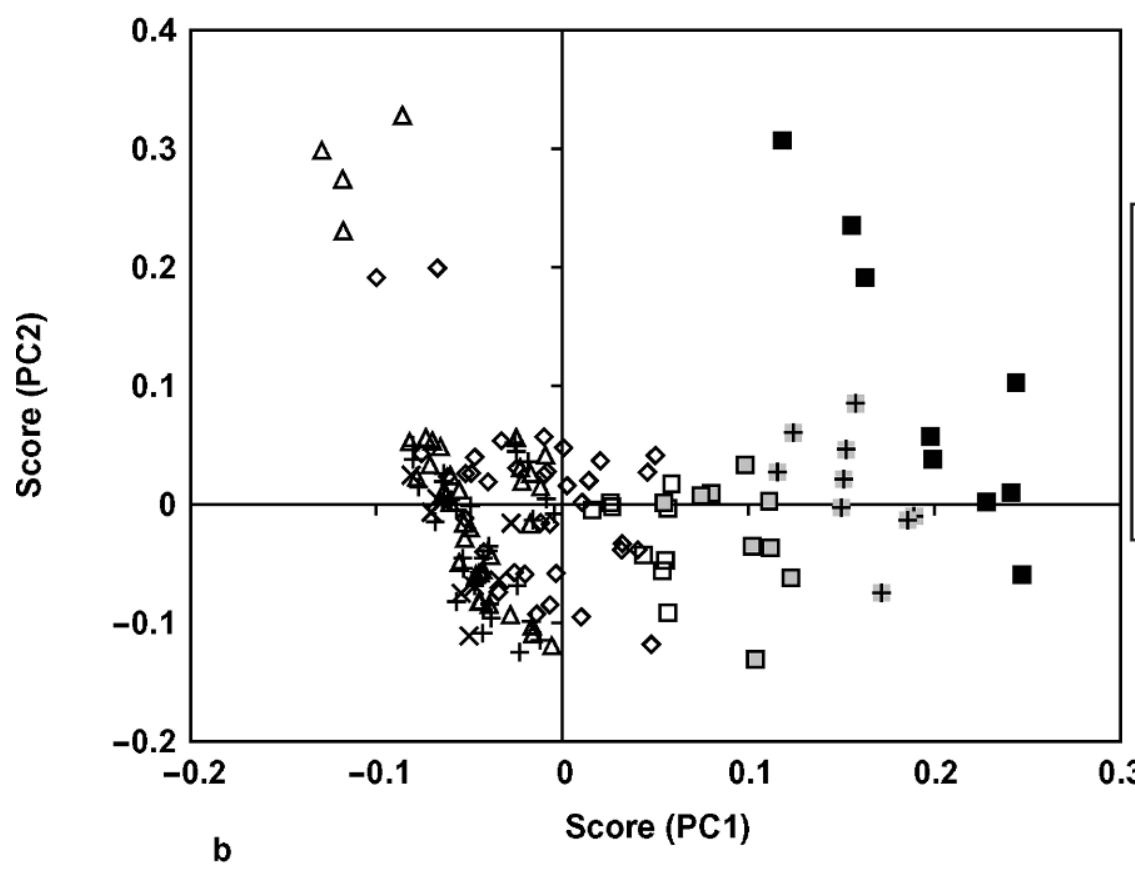

XOW

$+4 \mathrm{C}-1,2,4,8 \mathrm{~W}$

$\triangle 22 \mathrm{C}-1,2,4,8 \mathrm{~W}$

$\diamond 35 \mathrm{C}-1,2,4,8 \mathrm{~W}$

50C-1W

$\square 50 \mathrm{C}-2 \mathrm{~W}$

$+50 \mathrm{C}-4 \mathrm{~W}$

- 50C-8W

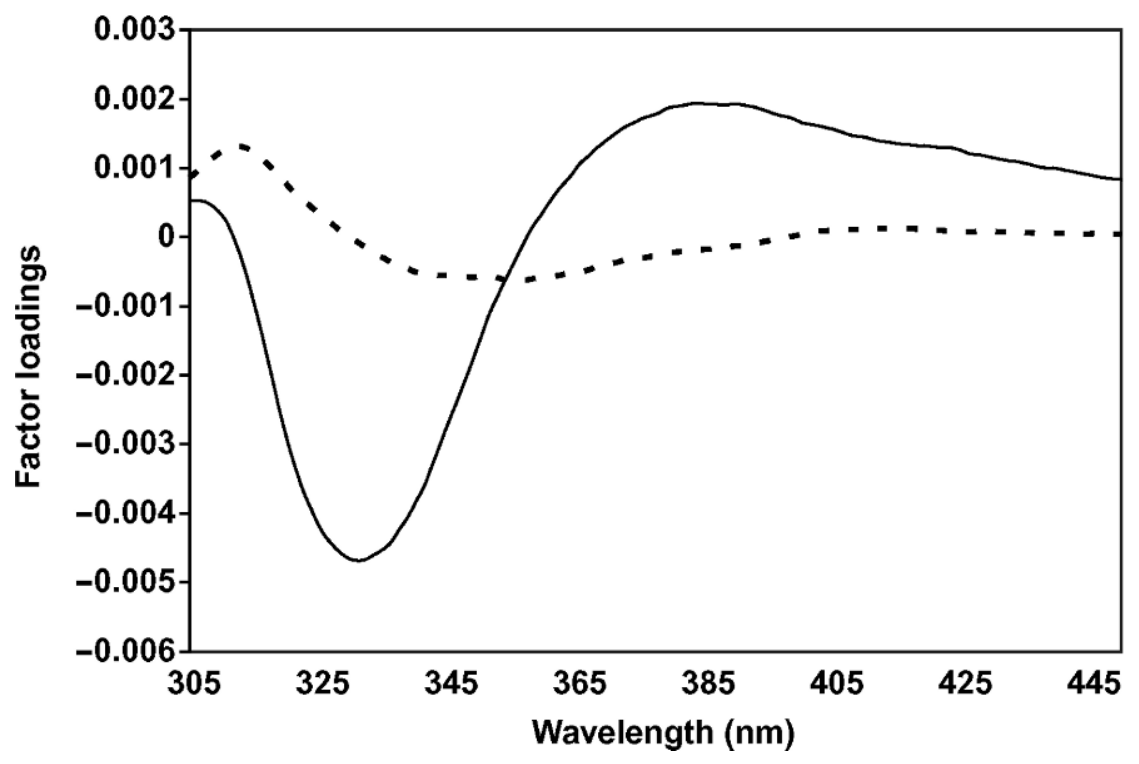

Figure 9. Principal component analysis (PCA) made on tryptophan emission spectra of the NDM samples: (a) Similarity map of the NDM samples before storage and after storage at $4,22,35$, and $50^{\circ} \mathrm{C}(\mathrm{C}$ in key) for $1,2,4$, and 8 wk (W in key); (b) factor loadings of the first 2 principal components; the lines in (b) indicate: PC1 (solid) and PC2 (dotted).

positive maximum at $315 \mathrm{~nm}$ and a negative band between 340 and $360 \mathrm{~nm}$. Principal component 1 and PC2 described a red shift and change in the fluorescence intensity during storage, respectively, and correlated well with the changes observed in the normalized spectra (Figure 6b).

In the riboflavin similarity maps (Figure 10a), storage at $50^{\circ} \mathrm{C}$ resulted in a larger decrease in the $\mathrm{PC} 1$ scores of the samples compared with the samples stored at the other temperatures. However, for some of the samples (A2, A3, B2, and B3), storage at 4, 22, and $35^{\circ} \mathrm{C}$ resulted in an increase in the PC1 scores. The factor loadings of PC1 presented an opposition between a negative band around $440 \mathrm{~nm}$ and a positive peak at $515 \mathrm{~nm}$ (Figure 10b). Thus, PC1 may correspond to the amounts of riboflavin and oxidation products in the samples. The factor loadings for PC2 showed a negative peak at $470 \mathrm{~nm}$ (Figure 10b). Similar to the first 2 PC 
a
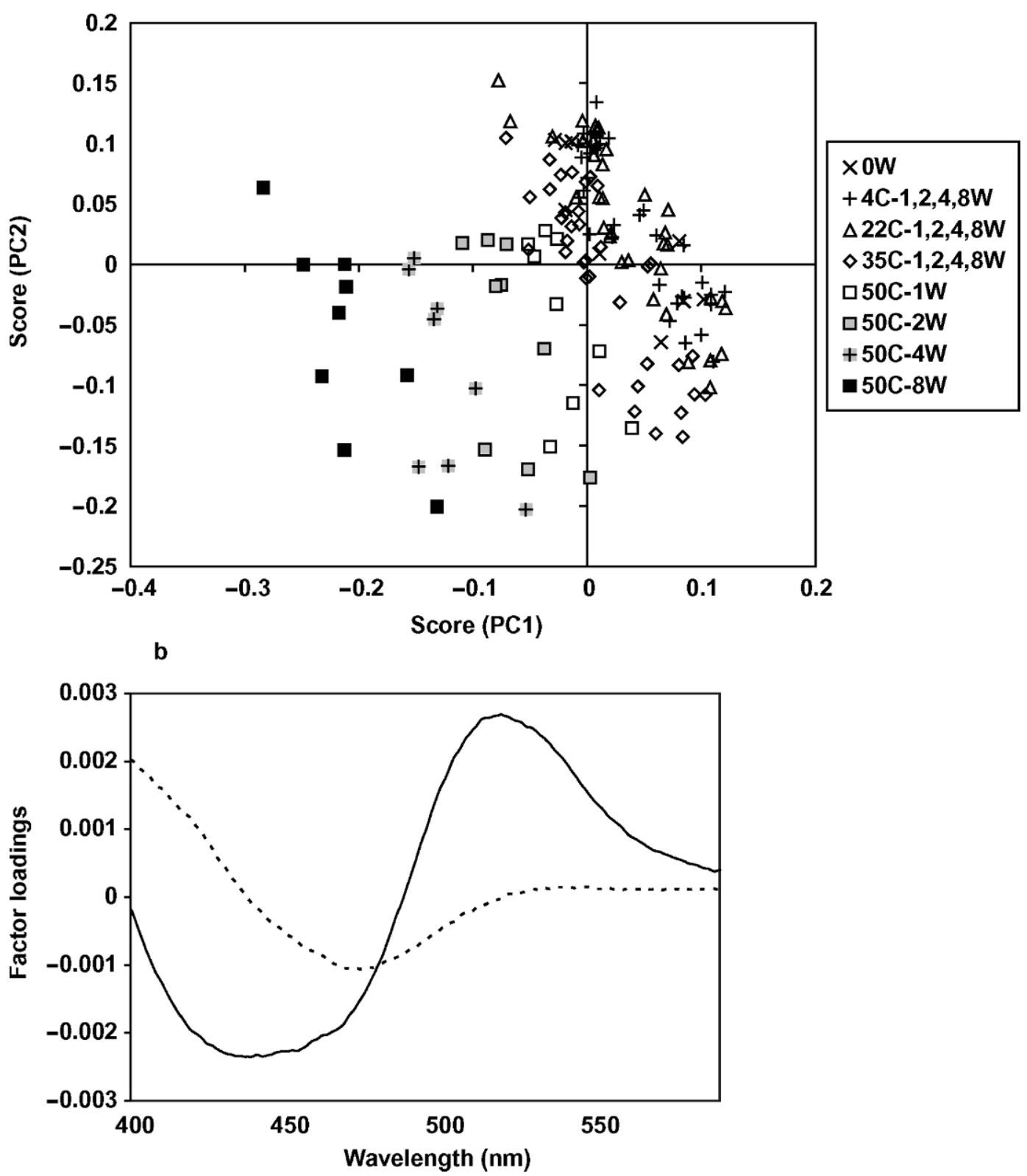

Figure 10. Principal component analysis (PCA) made on riboflavin emission spectra of the NDM samples: (a) Similarity map of the NDM samples before storage and after storage at $4,22,35$, and $50^{\circ} \mathrm{C}$ (C in key) for $1,2,4$, and 8 wk (W in key); (b) factor loadings of the first 2 principal components; the lines in (b) indicate: PC1 (solid) and PC2 (dotted).

of the riboflavin data for the samples before storage, PC1 and PC2 described formation of oxidation products and loss of riboflavin and lumichrome over time, respectively. Besides lumichrome, degradation of riboflavin may lead to formation of lumiflavin (Fox and Thayer, 1998). Lumiflavin is a fluorescent compound with emission maximum in the range of 516 to $522 \mathrm{~nm}$, which may explain the increases in the PC1 scores of sample $\mathrm{A} 2, \mathrm{~A} 3, \mathrm{~B} 2$, and $\mathrm{B} 3$ stored at relatively low storage temperatures $\left(4,22\right.$, and $\left.35^{\circ} \mathrm{C}\right)$. However, it is not clear why lumiflavin only formed in some of the samples during storage.

Overall, the factor loadings of the first 2 PC for the 4 fluorescence spectra of the samples before storage were similar to the PCA results of the samples during storage. It appears that similar factors are responsible for the variation in the samples before storage and their changes during storage, which indicated that biochemi- 
cal reactions such as the Maillard reaction, modification of the tryptophan environment, and degradation of riboflavin occurred during the manufacturing process and the storage of the samples.

It is known that flavor compounds are formed in the Maillard reaction (van Boekel, 1998). Oxidation of riboflavin can also lead to formation of strong off-flavors (Borle et al., 2001). Fluorescence analysis of the light-induced oxidation of cheese showed that degradation of porphyrins, chlorines, and riboflavin correlated closely with oxidized off-flavors detected in sensory analysis (Wold et al., 2005). Therefore, FFFS has the potential to monitor development of off-flavors in NDM during storage. Moreover, it is possible that the biochemical reactions occurring in NDM also affect its functionality. Thus, this investigation underlines the potential of fluorescence spectroscopy in combination with chemometrics as a fast, nondestructive method that can be applied to NDM for monitoring the Maillard reaction, oxidation of vitamins, and perhaps in monitoring development of off-flavors and changes in functionality.

\section{CONCLUSIONS}

This study demonstrated that FFFS, coupled with multivariate statistical methods, has potential as an analytical technique to monitor variation in NDM samples from different manufacturers and changes during storage. Biochemical reactions, such as Maillard reaction, modification of the tryptophan environment, and degradation of riboflavin occurred during the manufacturing process; the storage of the samples at relatively high temperatures $\left(50^{\circ} \mathrm{C}\right)$ accelerated these reactions. A further study with a larger sample size would be useful to identify the specific influences of the manufacturing conditions on the characteristics of the NDM before and during storage.

\section{REFERENCES}

American Dairy Products Institute. 1990. Standards for grades of dry milk including methods of analysis. Bulletin 916. ADPI, Chicago, IL

Andersen, C. M., M. Vishart, and V. K. Holm. 2005. Application of fluorescence spectroscopy in the evaluation of light-induced oxidation in cheese. J. Agric. Food Chem. 53:9985-9992.

Becker, E. M., J. Christensen, C. S. Freseriksen, and V. K. Haugaard. 2003. Front-face fluorescence spectroscopy and chemometrics in analysis of yogurt: Rapid analysis of riboflavin. J. Dairy Sci. 86:2508-2515.

Berg, H. E. 1993. Reactions of lactose during heat treatment of milk: A quantitative study. J. Agric. Food Chem. 40:707-713.

Berg, H. E., and M. A. J. S. van Boekel. 1994. Degradation of lactose during heating of milk. 1 Reaction pathways. Neth. Milk Dairy J. 48:157-175.

Bertrand, D., and C. N. G. Scotter. 1992. Application of multivariate analyses to NIR spectra of gelatinized starch. Appl. Spectrosc. 46:1420-1425.
Birlouez-Aragon, I., P. Sabat, and N. Gouti. 2002. A new method for discriminating milk heat treatment. Int. Dairy J. 12:59-67.

Borle, F., R. Sieber, and J. O. Bosset. 2001. Photo-oxidation and photoprotection of foods, with particular reference to dairy products: An update of a review article (1993-2000). Sci. Aliments 21:571-590.

Bourais, I., A. Amine, D. Moscone, and G. Palleschi. 2006. Investigation of glycated protein assay for assessing heat treatment effect in food samples and protein-sugar models. Food Chem. 96:485-490.

Christensen, J., V. T. Povlsen, and J. Sørensen. 2003. Application of fluorescence spectroscopy and chemometrics in the evaluation of processed cheese during storage. J. Dairy Sci. 86:1101-1107.

De Block, J., M. Merchiers, L. Mortier, A. Braekman, W. Ooghe, and R. Van Renterghem. 2003. Monitoring nutritional quality of milk powders: Capillary electrophoresis of the whey protein fraction compared with other methods. Int. Dairy J. 13:87-94.

De Block, J., M. Merchiers, and R. Van Renterghem. 1998. Capillary electrophoresis of the whey protein fraction of milk powders. A possible method for monitoring storage conditions. Int. Dairy J. 8:787-792.

Dillard, C. J., and A. L. Tappel. 1971. Fluorescent products of lipid oxidation of mitochondria and microsomes. Lipids 6:715-721.

Dufour, E., M. F. Devaux, and S. Herbert. 2001. Delineation of the structure of soft cheeses at the molecular level by fluorescence spectroscopy-relationship with texture. Int. Dairy J. 11:465473.

Dufour, E., G. Mazerolles, M. F. Devaux, G. Duboz, M. H. Duployer, and N. M. Riou. 2000. Phase transition of triglycerides during semi-hard cheese ripening. Int. Dairy J. 10:81-93.

Dufour, E., and A. Riaublanc. 1997. Potentiality of spectroscopic methods for the characterization of dairy products. I. Front-face fluorescence study of raw, heated and homogenized milks. Lait 77:657-670.

Ferrer, E., A. Alegría, R. Farré, G. Clemente, and C. Calvo. 2005. Fluorescence, browning index, and color in infant formulas during storage. J. Agric. Food Chem. 53:4911-4917.

Fox, J. B., and D. W. Thayer. 1998. Radical oxidation of riboflavin. Int. J. Vitam. Res. 68:174-180.

Guyomarc'h, F., F. Warin, D. D. Muir, and J. Leaver. 2000. Lactosylation of milk proteins during the manufacture and storage of skim milk powders. Int. Dairy J. 10:863-872.

Herbert, S., N. M. Riou, M. F. Devaux, A. Riaublanc, B. Bouchet, D. J. Gallant, and E. Dufour. 2000. Monitoring the identity and the structure of soft cheese by fluorescence spectroscopy. Lait 80:621-634.

Jones, A. D., C. M. Tier, and J. P. G. Wilkins. 1998. Analysis of the Maillard reaction products of $\beta$-lactoglobulin and lactose in skim milk powder by capillary elctrophoresis and electrospray mass spectrometry. J. Chromatogr. A. 822:147-154.

Kikugawa, K., and M. Beppu. 1987. Involvment of lipid oxidation products in the formation of fluorescent and cross-linked proteins. Chem. Phys. Lipids 44:277-296.

Kulmyrzaev, A., and E. Dufour. 2002. Determination of lactulose and furosine in milk using front-face fluorescence spectroscopy. Lait 82:725-735.

Leclére, J., and I. Birlouez-Aragon. 2001. The fluorescence of advanced Maillard products is a good indicator of lysine damage during the Maillard reaction. J. Agric. Food Chem. 49:46824687.

Liu, X. M., J. R. Powers, B. G. Swanson, H. H. Hill, and S. Clark. 2005. Modification of whey protein concentrate hydrophobicity by high hydrostatic pressure. Innov. Food Sci. Emerg. Technol. 6:310-317.

Matiacevich, S. B., and M. P. Buera. 2006. A critical evaluation of fluorescence as a potential marker for the Maillard reaction. Food Chem. 95:423-430.

Mestdagh, F., B. De Meulenaer, and J. De Clippeleer. 2005. Protective influence of several packaging materials on light oxidation of milk. J. Dairy Sci. 88:499-510. 
Morales, F. J., C. Romero, and S. Jiménez-Pérez. 1996. Fluorescence associated with Maillard reaction in milk and milk-resembling systems. Food Chem. 57:423-428.

Moreaux, V., and I. Birlouez-Aragon. 1997. Degradation of tryptophan in heated $\beta$-lactoglobulin-lactose mixtures is associated with intense Maillard reaction. J. Agric. Food Chem. 45:1905-1910.

Pellegrino, L., I. De Noni, and P. Resmini. 1995. Coupling of lactulose and furosine indices for quality evaluation of sterilized milk. Int. Dairy J. 5:647-659.

Schamberger, G. P., and T. P. Labuza. 2006. Evaluation of frontface fluorescence for assessing thermal processing of milk. J. Food Sci. 71:69-74.

Siegl, T., U. Schwarzenbolz, and T. Henle. 2000. Irreversivle casein oligomerisation and formation of fluorescent cross-link amino acids in dairy products. Czech. J. Food Sci. 18:72-73.

Skibsted, L. H. 2000. Light induced changes in dairy products. Pages 3-9 in Packaging of milk products. Int. Dairy Fed., Brussels, Belgium.
Thomas, M. E. C., J. Scher, S. Desobry-Banon, and S. Desobry. 2004. Milk powders ageing: Effect on physical and functional properties. CRC Crit. Rev. Food Sci. Nutr. 44:297-332.

Troyano, E., A. Olano, and I. Martinez-Castro. 1994. Changes in free monosaccharides during storage of dried milk. I. Agric. Food Chem. 42:1543-1545.

van Boekel, M. A. J. S. 1998. Effect of heating on Maillard reactions in milk. Food Chem. 62:403-414.

Van Renterghem, R., and H. De Block. 1996. Furosine in consumption milk and milk powders. Int. Dairy J. 6:371-382.

Wold, J. P., K. Jorgensen, and F. Lundby. 2002. Nondestructive measurement of light-induced oxidation in dairy products by fluorescence spectroscopy and imaging. J. Dairy Sci. 85:16931704.

Wold, J. P., A. Veberg, A. Nilsen, V. Iani, P. Juzenas, and J. Moan. 2005 . The role of naturally occurring chlorophyll and porphyrins in light-induced oxidation of dairy products. A study based on fluorescence spectroscopy and sensory analysis. Int. Dairy J. 15:343-353. 